\title{
UMA CLASSIFICAÇÃO QUIMICO-MINERALÓGICA DAS ROCHAS PLUTÔNICAS COMUNS E SUAS ASSOCIAÇÕES, MÉTODO E APLICAÇÕES
}

\author{
FRANÇOIS DEBON*, PATRICK LE FOR'T* e PIERRE SABATE***
}

\begin{abstract}
A CHEMICAL-MINERALOGICAL CLASSIFICATION OF COMMON PLUTONIC ROCKS AND THEIR MAGMATIC ASSOCIATIONS: METHODS AND APPLICATIONS. A classification has been proposed (Debon \& Le Fort 1983), based mainly on major element analytical data plotted in a coherent set of three simple chemical-mineralogical diagrams : $Q=\mathrm{Si} / 3-(\mathrm{K}+\mathrm{Na}+2 \mathrm{Ca} / 3) \mathrm{vs}$. $P=K-(\mathrm{Na}+\mathrm{Ca})$ ("nomenclature" diagram, adapted from La Roche 1964, 1966; parameters as gram-atoms $\times 10^{3}$ or millicátions in $100 \mathrm{~g}$ of rock); $\mathrm{A}=\mathrm{Al}-(\mathrm{K}+\mathrm{Na}+2 \mathrm{Ca})$ vs. $\mathrm{B}=\mathrm{Fe}+\mathrm{Mg}+\mathrm{Ti}$ ("characteristic minerals" diagram; parameters of Shand 1927, and La Roche 1964, again expressed as gram-atoms $\times 10^{3}$ in $100 \mathrm{~g}$ of rock); quartz-dark minerals-feldspars + muscovite ("Q-B-F" triangular diagram; parameters in weight percent, directly calculated from chemical analyses; La Roche 1964, Moine 1974). The procedure follows two complementary steps at two different levels, each using the three diagrams. The first is concerned with the individual sample; the sample is given a name (e.g. granite, granodiorite, gabbro,...) and its chemical and mineralogical characteristics are determined (e.g. its more or less aluminous character). The second one, more important, aims at defining the type of magmatic association to which the studied sample or group of sample belongs. Three main types of associations are distinguished: cafemic (approximately equivalent to the I-type of Chappell \& White 1974), aluminous (similar to the S-type), and alumino-cafemic (intermediate between the other two types). Subtypes are then distinguished among the cafemic and alumino-cafemic associations: tholeiitic (or gabbroic-trondhjemitic), calc-alkaline (or granodioritic), subalkaline (or monzonitic), alkaline (and peralkaline), etc. In the same way, numerous subtypes and variants are also distinguished among the aluminous associations using a set of complementary criteria such as quartz content, colour index, alkali ratio, quartz-dark minerals-alkalies relationships and alumina index. Although involving a new approach using partly new criteria, this classification is consistent with most of the divisions used in previous typologies. It has been put to use and tested on numerous examples and has shown to be easy to implement, coherent, comprehensive, and very discriminant. Based on chemical data, it may also be used in the typology of the volcanic rocks. As an example, the typology is applied to three plutonic belts of the Himalaya, South Tibet.
\end{abstract}

INTRODUÇÃO Uma classificação natural, coerente e exaustiva das rochas f́neas e de suas associaçōes magmáticas É uma exigência prévia indispensável a toda cartografia dos domínios cristalinos, a toda pesquisa sobre a gênese e a evolução dos magmas, a toda tentativa de correlação entre magmatismo e fenômenos geodinâmicos ou potencialidades metalíferas e, de um modo mais geral, a todo diálogo sobre o plutonismo ou o vulcanismo. Os numerosos trabalhos recentemente consagrados à pesquisa de tal classificaçảo demonstram o interesse desta última assim como demonstram a dificuldade que há para alcançar uma solução aprovada por todos.

Após vários petrólogos franceses e de outras nacionalidades, notadamente de $\mathrm{H}$. de $\mathrm{La}$ Roche, foi proposta recentemente uma classificação, baseada sobre dados químicos quantitativos (elementos maiores), do conjunto das rochas plutônicas (ou vulcânicas) comuns (dos gabros aos ... leucogranitos) e de suas associaçöes (Debon \& Le Fort 1983, 1984).

Apresenta-se aqui, sob uma forma condensada, o encaminhamento preconizado para se edificar essa classificação. Este trabalho agrupa e sintetiza os anteriores citados dos mesmos autores (Debon e Le Fort), é seguido e ilustrado por exemplos relativos a três cinturōes plutônicos do Himalaia, a sul do Tibete numa versão traduzida.para o Português pelo terceiro autor (Sabaté).

TIPOLOGIA DE UMA AMOSTRA Definir a tipologia de uma amostra consiste em the dar um nome e em destacar suas características químico-mineralógicas.

Nomenclatura $\mathrm{O}$ diagrama escolhido para designar uma rocha Ignea - chamado de diagrama de nomenclatura - asso- cia os dois parâmetros $\mathrm{Q}=\mathrm{Si} / 3-(\mathrm{K}+\mathrm{Na}+2 \mathrm{Ca} / 3)$ função de $P=[\mathrm{K}-(\mathrm{Na}+\mathrm{Ca})](\mathrm{La}$ Roche 1964, 1966; Fig. 1; ver Tabela 2 para exemplo de cálculo). Seu parâmetro Q é proporcional à carga ponderal em quartzo das rochas graníticas comuns. Como o quartzo, o feldspato potássico e os plagioclásios distribuem-se nos três vértices de um triângulo, este diagrama parece bem adaptado ao estabelecimento de uma nomenclatura baseada nos minerais claros.

Utilizando a nomenclatura de La Roche (1966) e Streckeisen $(1974,1976)$, superpusemos a este diagrama um novo quadro de classificação (Fig. 1) em que cada compartimento (1 a 12) corresponde a um grupo petrográfico (granito, adamelito, etc). Nossa nomenclatura baseia-se nesse quadro, cuja construção foi guiada pelas observações petrográficas com vistas a obter a melhor superposição possível com a classificação mineralógica clássca de Streckeisen $(1974,1976)$. Posto isto, distorçōes podem aparecer entre as duas classificaçōes: umas voluntárias (optou-se por estender o domínio dos granitos à custa do domínio dos adamelitos), as outras inerentes aos parâmetros escolhidos (caso das rochas muito ricas em minerais coloridos - biotita, ortopiroxênio, olivina etc. - ou em moscovita etc).

Caráter peraluminoso ou metaluminoso. Sua expressão mineralógica Segundo o valor positivo ou negativo de seu parâmetro (em átomo-g ou cátion) $\mathrm{A}=[\mathrm{Al}-(\mathrm{K}+\mathrm{Na}+$ 2Ca)] (Shand 1927; exemplo de cálculo na Tabela 2), uma rocha é dita peraluminosa ou metaluminosa.

É importante definir o caráter peraluminoso ou metaluminoso de uma rocha na medida que ele é o reflexo direto da natureza e das proporçōes dos seus minerais característicos 
Tabela 1-As 12 composições-tipo utilizadas camo sistema de referência para a tipologia químico-mineralógica das rochas plutônicas comuns.*

\begin{tabular}{|c|c|c|c|c|c|c|c|c|c|c|c|c|c|}
\hline \multicolumn{2}{|c|}{$\begin{array}{c}\text { Grupo } \\
\text { petrográfico } \\
\end{array}$} & gr & ad & gd & tp & sq & $\mathrm{mzq}$ & mzdq & $d q$ & $\mathbf{s}$ & $\mathbf{m z}$ & mzgo & go \\
\hline \multicolumn{2}{|c|}{$\begin{array}{l}\text { Número da casa } \\
\text { na figura } 1\end{array}$} & 1 & 2 & 3 & 4 & 5 & 6 & 7 & 8 & 9 & 10 & 11 & 12 \\
\hline & n & 94 & 194 & 208 & 60 & 5 & 10 & 27 & 36 & 2 & 8 & 6 & 20 \\
\hline \multirow{2}{*}{\multicolumn{2}{|c|}{$\begin{array}{l}\mathrm{SiO}_{2} \\
\mathrm{Al}_{2} \mathrm{O}_{3}\end{array}$}} & 73,67 & 71,58 & 67,02 & 62,98 & 66,34 & 62,89 & 59,13 & 55,22 & 60,40 & 57,48 & 53,83 & 47,02 \\
\hline \multirow{2}{*}{\multicolumn{2}{|c|}{$\mathrm{Fe}_{2} \mathrm{O}_{3} \mathrm{t}$}} & $\begin{array}{r}13,79 \\
\end{array}$ & 14,39 & 15,38 & 16,20 & 15,98 & 14,64 & 16,76 & 16,97 & 18,49 & 16,92 & 16,09 & 16,12 \\
\hline & & 1,54 & 2,31 & 4,01 & 5,55 & 3,66 & 5,07 & 6,91 & 8,16 & 4,31 & 6,16 & 8,67 & 10,04 \\
\hline \multicolumn{2}{|c|}{$\mathrm{MnO}$} & 0,03 & 0,05 & 0,08 & 0,10 & 0,07 & 0,09 & 0,13 & 0,15 & 0,12 & 0,12 & 0,16 & 0,16 \\
\hline \multicolumn{2}{|c|}{$\mathrm{MgO}$} & 0,32 & 0,60 & 1,43 & 2,34 & 0,37 & 1,55 & 2,56 & 4,17 & 0,70 & 2,34 & 3,52 & 8,15 \\
\hline \multicolumn{2}{|c|}{$\mathrm{CaO}$} & 0,84 & 1,80 & 3,77 & 5,65 & 1,12 & 3,57 & 5,56 & 7,98 & 2,48 & 5,10 & 6,99 & 11,89 \\
\hline \multirow{2}{*}{\multicolumn{2}{|c|}{$\begin{array}{l}\mathrm{Na}_{2} \mathrm{O} \\
\mathrm{K}, \mathrm{O}\end{array}$}} & 3,27 & 3,58 & 3,54 & 3,32 & 4,75 & 4,00 & 3,61 & 3,08 & 5,10 & 4,15 & 3,93 & 2,30 \\
\hline & & 5,13 & 4,23 & 2,99 & 1,67 & 5,73 & 4,44 & 3,04 & 1,39 & 6,10 & 4,49 & 2,74 & 0,60 \\
\hline \multicolumn{2}{|c|}{$\mathrm{TiO}_{2}$} & 0,21 & 0,29 & 0,50 & 0,57 & 0,46 & 0,75 & 0,83 & 0,94 & 0,46 & 0,86 & 1,26 & 1,26 \\
\hline \multirow{2}{*}{\multicolumn{2}{|c|}{$\begin{array}{l}\text { P.F. } \\
\text { Total }\end{array}$}} & 0,77 & 0,78 & 0,98 & 1,17 & 0,95 & 1,32 & 1,04 & 1,55 & 1,40 & 1,72 & 1,97 & 2,12 \\
\hline & & 99,57 & 99,61 & 99,70 & 99,55 & 99,43 & 99,32 & 99,57 & 99,61 & 99,56 & 99,34 & 99,16 & 99,66 \\
\hline \multicolumn{2}{|l|}{$\mathrm{Ba}$} & 414 & 552 & 579 & 378 & 229 & 481 & 639 & 335 & 718 & 700 & 850 & 175 \\
\hline \multicolumn{2}{|l|}{ Co } & 41 & 41 & 49 & 54 & 22 & 32 & 43 & 57 & 6-11 & 32 & 38 & 66 \\
\hline \multicolumn{2}{|l|}{$\mathrm{Cr}_{\mathrm{r}}$} & $2-11$ & $7-13$ & $19-21$ & 37 & $0-10$ & $15-20$ & $28-30$ & 65 & $0-10$ & $37-41$ & 55 & 299 \\
\hline \multicolumn{2}{|l|}{$\mathrm{Cu}$} & $3-12$ & $3-12$ & $10-16$ & $10-17$ & $11-15$ & $14-17$ & 22-15 & $38-40$ & $0-10$ & $60-63$ & $21-24$ & $61-62$ \\
\hline \multicolumn{2}{|l|}{$\mathrm{Ni}$} & $2-10$ & $6-12$ & $17-19$ & 32 & $0-10$ & $10-14$ & $23-25$ & 50 & $0-19$ & $21-25$ & 42 & 125 \\
\hline \multicolumn{2}{|l|}{$\begin{array}{l}\mathrm{Rb} \\
\mathrm{Sr}\end{array}$} & 235 & 171 & 103 & 48 & 236 & 163 & 108 & 39 & 157 & 142 & 65 & $15-29$ \\
\hline Sr & & 126 & 195 & 322 & 303 & 92 & 299 & 417 & 358 & 284 & 650 & 848 & 417 \\
\hline \multicolumn{2}{|l|}{ V } & $17-21$ & $33-34$ & 79 & 118 & $19-21$ & 71 & 121 & 200 & $7-12$ & 115 & 205 & 274 \\
\hline \multicolumn{2}{|l|}{ Q } & 185 & 172 & 149 & 140 & 81 & 83 & 82 & 83 & 1 & & 3 & 33 \\
\hline \multicolumn{2}{|l|}{$\mathbf{P}$} & -11 & -57 & -117 & -172 & -51 & -99 & -150 & -212 & -79 & -129 & -194 & -273 \\
\hline \multicolumn{2}{|l|}{ A } & 26 & 13 & -10 & -27 & -2 & -44 & -50 & -82 & -20 & -80 & -120 & 195 \\
\hline \multicolumn{2}{|c|}{$\begin{array}{l}\text { B } \\
\text { F }\end{array}$} & 30 & 48 & 92 & 135 & 61 & 111 & 160 & 218 & 78 & 147 & 212 & 346 \\
\hline \multirow{2}{*}{\multicolumn{2}{|c|}{$\begin{array}{l}\mathrm{F} \\
(\mathrm{Na}+\mathrm{K})\end{array}$}} & 340 & 335 & 314 & 280 & 413 & 361 & 313 & 254 & 465 & 380 & 312 & 176 \\
\hline & & 214 & 205 & 178 & 143 & 275 & 223 & 181 & 129 & 295 & 230 & 185 & 87 \\
\hline \multicolumn{2}{|c|}{$\mathrm{K} /(\mathrm{Na}+\mathrm{K})$} & 0,51 & 0,44 & 0,36 & 0,25 & 0,44 & 0,42 & 0,36 & 0,23 & 0,44 & 0,42 & 0,31 & 0,15 \\
\hline \multicolumn{2}{|c|}{$\mathrm{Mg} /(\mathrm{Fe}+\mathrm{Mg})$} & 0,30 & 0,34 & 0,42 & 0,46 & 0,16 & 0,38 & 9,43 & 0,50 & 0,25 & 0,43 & 0,45 & 0,62 \\
\hline \multirow[t]{2}{*}{$\%$} & $\begin{array}{l}\text { Quartzo } \\
\text { Minerais }\end{array}$ & 33,3 & 31,0 & 26,8 & 25,2 & 14,6 & 15,0 & 14,8 & 14,9 & 2,2 & 5,0 & 5,6 & 6,0 \\
\hline & $\begin{array}{l}\text { escuros } \\
\text { Feldspatos }\end{array}$ & 5,4 & 8,6 & 16,6 & 24,3 & 11,0 & 20,0 & 28,8 & 39,3 & 14,1 & 26,5 & 38,2 & 62,3 \\
\hline Peso & moscov & 61,3 & 60,4 & 56,6 & 50,5 & 74,4 & 65,0 & 56,4 & 45,8 & 83,7 & 68,5 & 56,2 & 31,7 \\
\hline
\end{tabular}

* Essas 12 composiçôes-tipo são valores médios obtidos a partir de um conjunto homogêneo de 670 amostras colhidas pelos autores em plútons do Afeganistão e analisados por K. Govindaraju no quantômetro (espectrometria de emissão) do CRPG, Nancy, França (Debon et. al. 1987). A repartição dessas amostras em 12 grupos petrográficos baseia-se sobre sua localização dentro do quadro de classificação do diagrama de nomenclatura (Fig. 1): gr, granito; ad, adamelito; gd, granodiorito; to, tonalito; sq, quartzo-sienito; mzq, quartzo-monzonito; mzdq, quartzo-monzodiorito; $d q$, quartzo-diorito; $s$, sienito; mz, monzonito; mzgo, monzogabro; go, gabro; $n$, número de amostras analisadas; $\mathrm{Fe}_{2} \mathrm{O}_{3} \mathrm{t}=$ ferro total, dosado sob forma férrica; $L I_{\text {. }}=$ perda ao fogo. Os teores em elementos-traço são dados em p.p.m. O significado dos parâmetros e o modo de cálculo são dados na tabela 2. Segundo Debon \& Le Fort (1983)

(minerais outros que o quartzo e o feldspato, incluindo principalmente os coloridos e a moscovita). Isso posto, o parâmetro A não permite por si só apreender com precisão essa expressão mineralógica; para conseguí-la, ê necessário associá-lo com outro parâmetro tal como $\mathrm{B}=\mathrm{Fe}+\mathrm{Mg}+\mathrm{Ti}$ [parâmetro $\mathrm{B}$, o qual La Roche (1964) mostrou ser proporcional à carga ponderal em minerais coloridos nas rochas graníticas comuns (Tab. 2)].
O diagrama $\mathrm{A}$ em função de $\mathrm{B}$ assim realizado é chamado de diagrama dos minerais característicos ou do balanço aluminoso (Fig. 2). Sua metade superior (A positivo) corresponde ao domínio das rochas e dos minerais peraluminosos e sua metade inferior, ao dos metaluminosos. Ele permite apreender muito rapidamente a natureza e as proporçōes relativas dos principais minerais característicos suscetiveis de ser representados numa rocha. Sua divisão em seis setores - nu- 


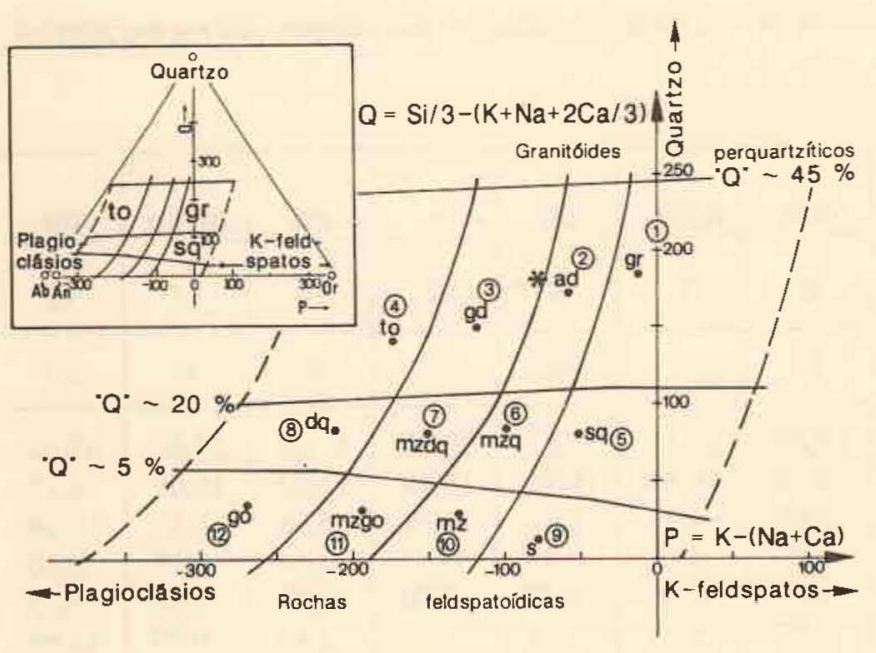

Figura 1 - Diagrama Q-P Ou diagrama de nomenclatura para as rochas igneas comuns segundo La Roche (1964, 1966), modificado. Seus parâmetros sâo expressos em átomo-grama $X$ $10^{3}$ (milicátion) em $100 \mathrm{~g}$ de rocha ou de mineral (ver tabela 2 para exemplos de cálculo). Cada compartimento do quadro corresponde a um grupo petrográfico: 1. gr, granito; 2. ad, adamelito; 3. gd, granodiorito; 4. to, tonalito/(trondhjemito); 5. sq, quartzo-sienito; 6. mzq, quartzo-monzonito; 7. mzdq, quartzo-monzodiorito; 8. dq, quartzo-diorito, (quartzo-gabro, quartzo-anortosito); 9. $\mathrm{s}$, sienito, $10 . \mathrm{mz}$, monzonito; $11 . \mathrm{mzgo}$, monzogabro (monzodiorito); 12. go, gabro (diorito, anortosito). As 12 composições-tipo adotadas como sistema de referência (Tab. 1) são indicadas por pontos pretos. $O$ asterisco corresponde ao exemplo desenvolvido na tabela 2 . " $Q "$ " = quartzol(quartzo + feldspatos + moscovita), \% em volume.

Para as rochas vulcânicas, a nomenclatura ê a seguinte: 1. riolito; 2. delenito; 3. riodacito; 4. dacito; 5. quartzo-traquito; 6. quartzo-latito; 7. quartzo-latiandesito; 8. quartzo-andesito (quartzo-basalto); 9. traquito; 10. latito; 11. latibasalto (latiandesito); 12 basalto (andesito). Para permitir a reprodução com precisão deste quadro de classificação são dadas as seguintes coordenadas: dentro de cada par de dados, o primeiro valor é o do parâmetro $P$ e o segundo, do $Q$; os valores fora de parênteses correspondem aos pontos de intersecção das linhas do quadro; os valores entre parênteses correspondem a pontos quaisquer das linhas do quadro: $-216,238 ;-119,242 ;-59$, $244 ;-17,245 ; 105,250 ;(-230,190 ;-134,190 ;-71 ; 190 ;-29$, $190 ; 90,190 ;-256,132 ;-156,136 ;-89,137 ;-44,140 ; 75$, 140); $-274,100 ;-172,104 ;-103,107 ;-55,109 ;(-30,110)$; 64,$110 ;(-187,79 ;-125,70 ;-69,77) ;-311,57 ;(-224,57)$; $-205,55 ;-143,48 ;-88,43 ;(-40,38) ; 30,26 ;-377,0 ;-257,0$; - 188, 0;-117, 0; 16, 0. Segundo Debon \& Le Fort (1983).

merados de I a III no domínio peraluminoso e de IV a VI no outro domínio - por semi-retas vindas da origem facilita essas estimativas. Assim, em primeira análise, pode-se considerar que as rochas localizadas no setor I têm duas micas, com moscovita > biotita (em volume); II, rochas com duas micas, com biotita > moscovita; III, rochas com biotita; IV, rochas com biotita, anfibólio \pm piroxênio; $\mathrm{V}$, rochas com clinopiroxênio, anfibólio, ...; e VI, somente as rochas excepcionais (carbonaticas, por exemplo) deveriam estar nele. Praticamente, o número do setor no qual localiza-se uma amostra qualquer deverá sempre aparecer em sua definição.

Em contrapartida do seu forte poder discriminante, esse diagrama A-B exige análises químicas muito confiáveis.
Cargas em quartzo, coloridos e feldspatos (+moscovita) Rochas que recebem a mesma denominaçao (por exemplo, granito) podem apresentar cargas muito diferentes em quartzo (Q), coloridos (B) e feldspatos (F). É então importante dar com precisão esse aspecto da definição tipológica de uma amostra. Duas condições são necessárias:

a. Calcular as cargas Q, B e F da amostra. Sabe-se (La Roche 1964) que as cargas ponderais em quartzo (Q), coloridos (B) e feldspatos (+moscovita) (F) de uma rocha granítica comum podem ser facilmente calculadas a partir dos dados químicos, com a ajuda de parâmetros $\mathrm{Q}=[\mathrm{Si} / 3-(\mathrm{K}+\mathrm{Na}+$ $2 \mathrm{Ca} / 3)], \mathrm{B}=\mathrm{Fe}+\mathrm{Mg}+\mathrm{Ti}$ e $\mathrm{F}=[555-(\mathrm{Q}+\mathrm{B})](\mathrm{ex}-$ pressos em átomo-grama $\times 10^{3}$ ou milicátion para $100 \mathrm{~g}$ de rocha; ver tabela 2 para exemplo de cálculo).

b. Dispor de um sistema de composições referenciais com as quais possamos confrontar a amostra estudada. $\mathrm{O}$ sistema que escolhemos é o objeto da tabela 1 . Ele reúne 12 composições-tipo correspondendo aos 12 grupos do diagrama de nomenclatura (Fig. 1).

$\mathrm{Na}$ prática, as cargas $\mathrm{Q}, \mathrm{B}$ e $\mathrm{F}$ da amostra estudada são calculadas e depois transformadas em porcentagens ponderais (Tab. 2) antes de serem reportadas num diagrama triangular quartzo (Q)-coloridos (B)-fedspatos (+moscovita) (F) (diagrama $Q-B-F$; Moine 1974), onde aparecem as 12 fácies-tipo do sistema de referência (Fig. 3). A amostra poderá, desta forma, ser facilmente comparada com a fáciesutipo possuindo

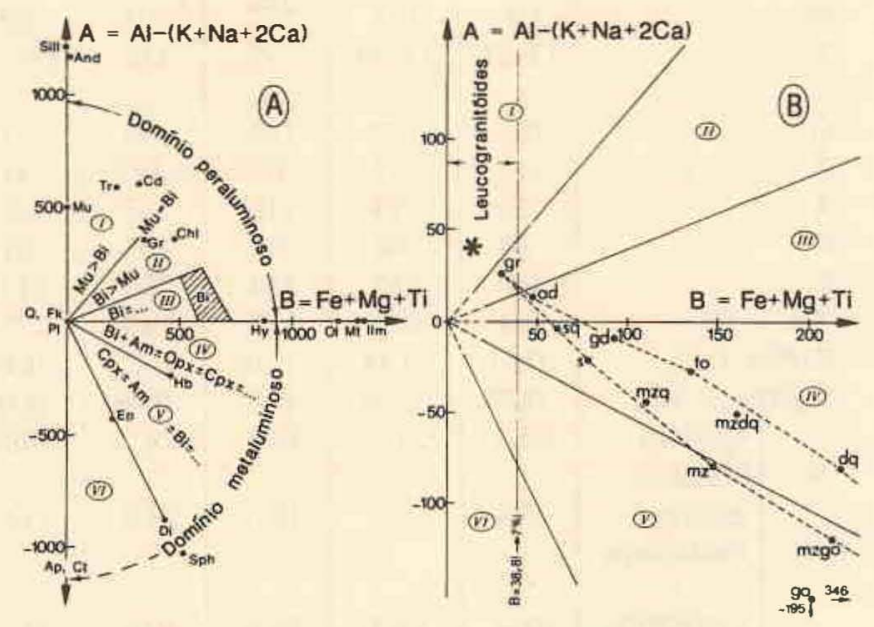

Figura 2 - Diagrama A-B ou diagrama dos minerais característicos ou do balanço aluminoso. Os parâmetros são expressos em átomo grama $x 10^{3}$ (milicátion) em $100 \mathrm{~g}$ de rochas ou de minerais (ver tabela 2 para exemplo de cálculo). Cada um de seus setores (numerados de I a VI) corresponde a uma composição mineralógica especifica (ver diagrama da esquerda e o texto). Partindo das composiçóes mineralogicas especificas reais ou teóricas, os seguintes minerais foram postos no diagrama à esquerda,(A): Am, anfibólio; And, andalusita; $A p$, apatita; Bi, biotita (domínio listrado); $\mathrm{Cd}$, cordierita; $\mathrm{Chl}$, clorita; $C t$, calcita; Di, diopsídio; $E p$, epidoto; $F k$, feldspato potássico; $\mathrm{Gr}$, granada piralspita; $\mathrm{Hb}$, hornblenda; $\mathrm{Hy}$, hiperstênio; Ilm, ilmenita; $M t$, magnetita; $M u$, moscovita; Ol, olivina; $\mathrm{Pl}$, plagioclásio; $Q$, quartzo; Sill, silimanita; Sph, esfênio; $T r$, turmalina. No diagrama da direita, $(B)$, as 12 composiçóes-tipo (Tab. 1) são representadas por pontos pretos; o asterisco corresponde ao exemplo desenvolvido na tabela 2. Segundo Debon \& Le Fort (1983) 
a mesma nomenclatura e definida então como rica, banal ou pobre em quartzo, coloridos e feldspatos (+ moscovita) (tab. 2).

Outras características Chegando neste ponto da definição tipológica de uma amostra, resta ainda, sempre em comparação com o sistema de composiçōes-tipo (Tab. 1): caracterizar a amostra a nível de carga em alcalinos $(\mathrm{Na}+\mathrm{K})$ e de suas razōes $\mathrm{K} /(\mathrm{Na}+\mathrm{K})$ e $\mathrm{Mg} /(\mathrm{Fe}+\mathrm{Mg})$; e evidenciar todas as anomalias de composição, relativas a um ou outro de seus elementos maiores, de seu traços ou até de sua perda ao fogo.

A tabela 2 e o item de Aplicação no Himalaia, dão exemplos de tipologia químico-mineralogica de amostras.

TIPOLOGIA DE UMA ASSOCIAÇÃO Uma associação magmática pode ser definida como um conjunto de rochas ígneas apresentando características comuns e proveniente da mesma estrutura (plúton, batólito, cinturão plutônico etc.). Para definir a tipologia de uma associação propusemos uma aproximação em duas etapas.

Primeira etapa: discriminação dos três grandes tipos de associaçōes magmáticas Vários autores (e.g. Chappell \& White 1974, La Roche 1979, etc.) sublinharam a importância do caráter mais ou menos aluminoso de uma associação magmática como critério de discriminação. Este caráter está, de fato, estreitamente correlacionado com as modalidades genéticas (natureza do material fonte, contexto geodinâmico etc.) e as potencialidades metalogenéticas do material ígneo. Isso explica que tenhamos retido tal tipo de caráter como critério básico para a tipologia das associações magmáticas.

Dentro dessa perspectiva, o diagrama dos minerais característicos ou o do balanço aluminoso revela-se muito perti-

Tabela 2 - Exemplo de cálculo dos parâmetros utilizados* e de tipologia químico-mineralogica de uma amostra**

\begin{tabular}{|c|c|c|c|c|c|c|c|c|}
\hline & a & Peso & b & $\mathrm{a} / \mathrm{b} \times 10^{3}$ & \multicolumn{4}{|c|}{ Parâmetro } \\
\hline & 6xido \% & molecular & fator & átomo-grama & \multirow{2}{*}{\multicolumn{2}{|c|}{$\mathrm{Q}=[\mathrm{Si} / 3-(\mathrm{K}+\mathrm{Na}+2 \mathrm{Ca} / 3)]$}} & & \\
\hline $\mathrm{SiO}_{2}$ & 74,16 & 60 & 60 & 1.236 & & & $=$ & 178 \\
\hline $\mathrm{Al}_{2} \mathrm{O}_{3}$ & 14,89 & 102 & 51 & 292 & \multicolumn{2}{|c|}{$P=[K-(N a+C a)]$} & $=$ & -78 \\
\hline $\mathrm{Fe}_{2} \mathrm{O}_{3} \mathrm{t}$ & 0,59 & 160 & 80 & 7 & \multicolumn{2}{|c|}{$A=[A l-(K+N a+2 C a)]$} & $=$ & 41 \\
\hline $\mathrm{MnO}$ & 0,10 & 71 & 71 & 1 & \multicolumn{2}{|c|}{$B=(F e+M g+T i)$} & $=$ & 12 \\
\hline $\mathrm{MgO}$ & 0,16 & 40 & 40 & 4 & \multicolumn{2}{|c|}{$F=[555-(Q+B)]$} & $=$ & 365 \\
\hline $\mathrm{CaO}$ & 0,75 & 56 & 56 & 13 & \multicolumn{2}{|c|}{$(\mathrm{Na}+\mathrm{K})$} & $=$ & 225 \\
\hline $\mathrm{Na}_{2} \mathrm{O}$ & 4,49 & 62 & 31 & 145 & \multicolumn{2}{|c|}{$\mathrm{K} /(\mathrm{Na}+\mathrm{K})$} & $=$ & 0,36 \\
\hline $\mathrm{K}_{2} \mathrm{O}$ & 3,75 & 94 & 47 & 80 & \multicolumn{2}{|c|}{$\mathrm{Mg} /(\mathrm{Fe}+\mathrm{Mg})$} & $=$ & 0,36 \\
\hline $\mathrm{TiO}_{2}$ & 0,06 & 80 & 80 & 1 & \multirow{3}{*}{\multicolumn{2}{|c|}{$\begin{array}{cl} & \mathrm{Q} \text { (quartzo) } \\
\text { Peso } & \mathrm{B} \text { (minerais escuros) } \\
\% & \mathrm{~F} \text { (feldspatos + muscovita) }\end{array}$}} & $=$ & 32,1 \\
\hline P.F. & 0,59 & & & & & & $=$ & 2,2 \\
\hline & & & & & & & $=$ & 65,7 \\
\hline Total & 99,54 & - & & & & & & \\
\hline
\end{tabular}

* Elementos-traços (p.p.m): $\mathrm{Ba} 29, \mathrm{Co} 72, \mathrm{Cr}<10, \mathrm{Cu}<10, \mathrm{Ni}<10, \mathrm{Rb} 287, \mathrm{Sr} 12, \mathrm{~V}<10$

** A amostra estudada é a de um dique do cinturão Norte-Himalaia (Sul do Tibete) analisado com o quantômetro do CRPG, Nancy, França, por K. Govindaraju. Segundo a classificação proposta, trata-se de um granodiórito (proximo dos adamelitos) (Fig. 1), peraluminoso (l) (Fig. 2), muito pobre em coloridos (leucocrático) mais rico em quartzo, feldspatos + moscovita (Fig. 3) e alcalis (por excesso de $\mathrm{K}$ e $\mathrm{Na}$ ), muito empobrecido em $\mathrm{Ca}, \mathrm{Ba}, \mathrm{Cr}, \mathrm{Cu}, \mathrm{Ni}, \mathrm{Sr}$ e $\mathrm{V}$ mas rico em $\mathrm{Rb}$, com razão $\mathrm{Mg} /(\mathrm{Fe}+\mathrm{Mg}$ ) bastante fraca. A localização desta amostra no setor I do diagrama dos minerais caracteristicos (Fig. 2) sugere que se trata de uma rocha cm duas micas, com moscovita > biotita (em volume). O microscópio confirma essas informações e permite acrescentar que esta rocha contém também granadas. $\mathrm{Fe}_{2} \mathrm{O}_{3} t=$ ferro total, dosado sob forma férrica; $\mathrm{P} . \mathrm{F}$. = perda ao fogo. Átomo-grama $x 10^{3}=$ milicátion. Os parâmetros $B=(F e+M g+T i)$ e $M g /(F e+M g)$ são calculados com $F e=$ ferro total. Segundo Debon \& Le Fort (1984)

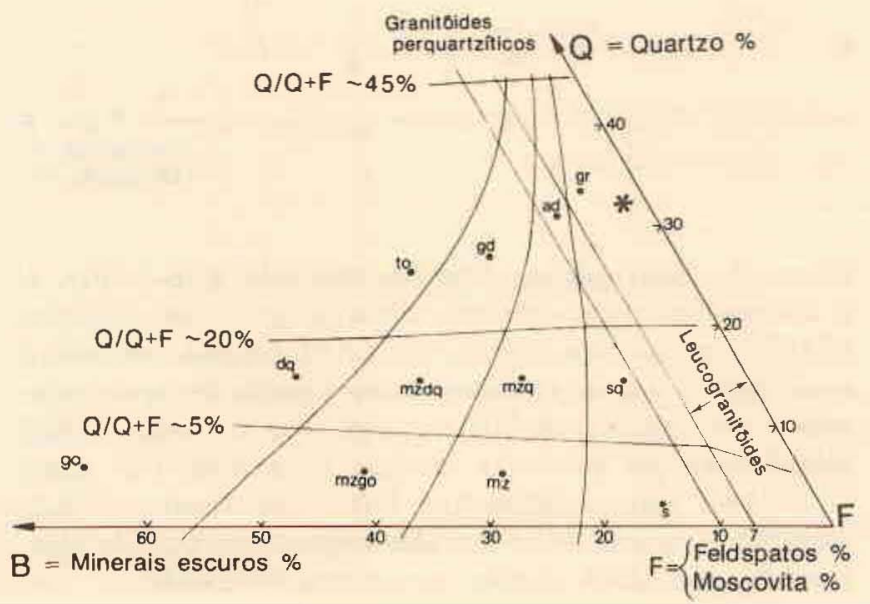

Figura 3 - Diagrama triangular quartzo-coloridos-feldspatos + moscovita ou diagrama $Q-B-F$. Os parâmetros são calculados a partir dos dados químicos e expressos em percentagens ponderais (ver tabela 2 para exemplo de cálculo). O quadro de classificação da figura 1 foi transposto neste triângulo e as 12 composições-tipo do sistema de referência (Tab. 1) são, aqui também, representadas por pontos pretos. Todos os feldspatos, neste diagrama, sendo agrupados num mesmo ponto, o quadro náo pode ser mais utilizado como quadro de nomenclatura; seu papel consiste simplesmente em facilitar a apreensão das caracterlsticas de uma amostra, de nomenclatura conhecida, concernente a suas cargas em quartzo, feldspatos (+ moscovita) e coloridos. $O$ asterisco corresponde ao exemplo desenvolvido na tabela 2. Segundo Debon \& Le Fort (1983) 
nente. Levando em conta a localização e a inclinação do seu trend evolutivo nesse diagrama (Fig. 4), somos levados a classificar as associaçōes magmáticas em três grandes tipos de associaçöes: cafêmicas, alumino-cafêmicas e aluminosas.

As principais características de cada um desses três tipos de associações são expostas na figura 4 e no "Glossário".

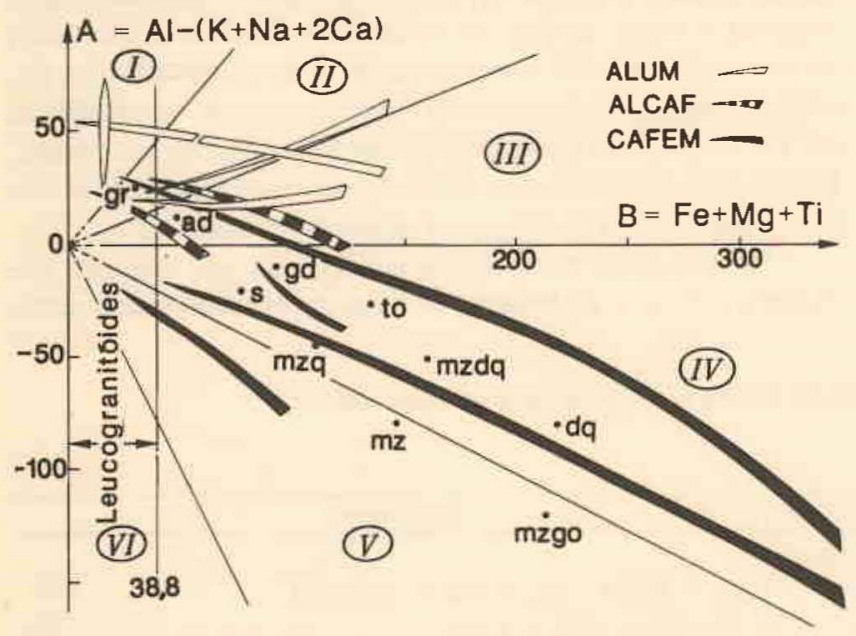

Figura 4 - Discriminaçāo dos três grandes tipos de associaçôes magmáticas por meio do diagrama dos minerais caracteristicos (Fig. 2): aluminoso (ALUM), alumino-cafêmico (ALCAF) e cafêmico (CAFEM). Alguns exemplos pertencendo a cada um desses três tipos são representados. Outras explicaçōes, no texto, "Glossário" e na figura 2

Numa primeira aproximação e do ponto de vista puramente descritivo, nossas associaçōes cafêmicas e aluminosas correspondem respectivamente às dos tipos I e S de Chappell \& White (1974).

No plano genético, podemos, em primeira análise, considerar que:

-as associações cafêmicas representariam um material de origem ora exclusivamente mantélica, ora de um modo mais geral um material híbrido, quer dizer ao mesmo tempo mantélico e crustal continental;

-as associaçōes alumino-cafêmicas teriam elas também uma origem híbrida, geralmente com dominante continental;

-as associaçōes aluminosas derivariam essencial ou totalmente de uma anatexia de crosta continental.

Segunda etapa: discriminação dentro de cada um dos trés grandes tipos de associaçōes magmáticas Esta segunda etapa consiste em dar com precisão a tipologia das associações. A esse nível, os critérios de discriminação e o vocabulário usado vão ser totalmente diferentes, segundo se trata de associações cafêmicas ou alumino-cafêmicas ou de associaçōes aluminosas.

DISCRIMINAÇÃO DAS DIFERENTES ASSOCIAÇŌES CAFÊMICAS A diversificaçāo das associaçōes cafêmicas está ligada, em prioridade, aos jogos relativos do quartzo, dos feldspatos e dos minerais coloridos. Isso explica que o diagrama triangular Q-B-F seja, em paralelo com o diagrama de nomenclatura (Fig. 5 e 6), particularmente favorável para evidenciar as diferentes categorias de associaçōes cafêmicas.

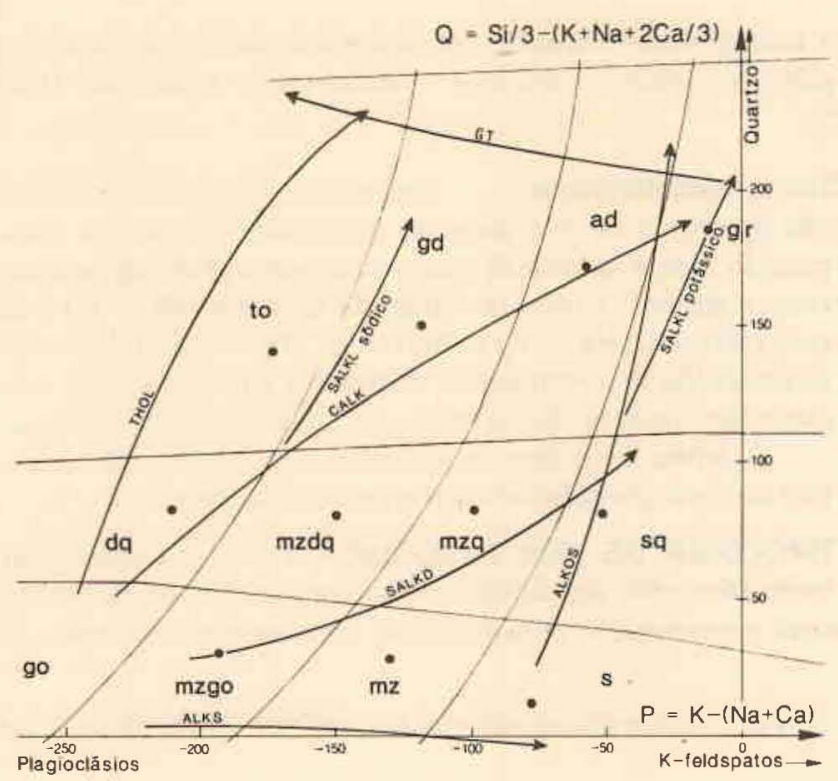

Figura 5 - Aplicação do diagrama de nomenclatura (Fig. 1) para a discriminação das diferentes associações de tipo cafêmicas ou alumino-cafêmicas. Levando em conta a localização $e o$ trend evolutivo de tais associações dentro do diagrama $e$ dentro do triângulo Q-B-F' (Fig. 6), é fácil classificá-los em diferentes subtipos e variantes (tolettico, calcialcalino, subalcalino, alcalino etc.) (ver texto, "Glossário" e figura 6). Trends característicos de uma dessas associaçóes foram reportados nesta figura: toleítico (ou gabro-trondhjemítico), THOL; calcialcalino (ou granodioritico), CALK; subalcalino (ou monzonítico), respectivamente escuro, $S A L K D$, e claro, SALKL; alcalino, respectivamente saturado, $A L K S$, e supersatrado, $A L$ KOS; granito-trondhjemíticos, GT.

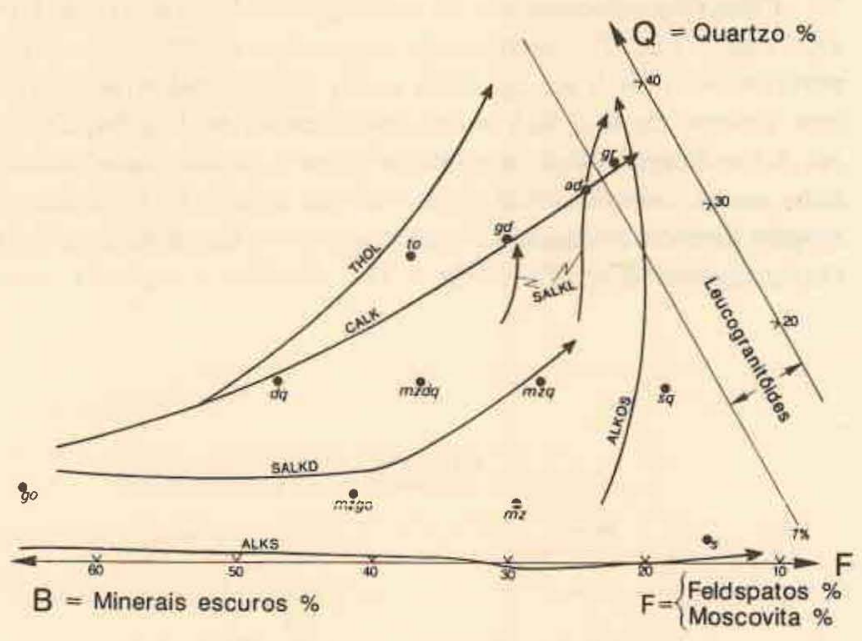

Figura 6 - Aplicação do diagrama triangular Q-B-F (Fig. 3) à discriminação das diferentes associações de tipo cafêmico (CAFEM) ou alumino-cafêmico (ALCAF). Levando em conta a localização e o trend evolutivo de tais associaçöes neste triângulo e no diagrama de nomenclatura (Fig. 5), torna-se fácil classificá-los em diferentes subtipos $e$ variantes (ver texto, "Glossário" e figura 5): toletitico, THOL; calcialcalino, CALK; subalcalino escuro, SALKD; subalcalino claro, SALKL; alcalino saturado, ALKS; alcalino supersaturado ALKOS 
As diferentes categorias (subtipos, variantes) de associações cafêmicas que as dois diagramas permitem identificar segundo a localização e o trend evolutivo que ali mostram essas associações - são as seguintes:

\section{SUBTIPOS}

VARIANTES

-Toleftico (ou gabro-trondhjemítico)

-Calcialcalino (ou granodiorítico)

-Subalcalino (ou monzonítico)

-Alcalino (e peralcalino)

As principais características de cada um dos quatro subtipos e das seis variantes são expostas nas figuras 5 e 6 , assim como no "Glossário".

As diferentes categorias de associações cafêmicas assim postas em evidência correspondem a uma divisão clássica das séries magmáticas, tanto plutônicas quanto vulcânicas.

\section{DISCRIMINAÇÃO DAS DIFERENTES ASSOCIAÇŌES} ALUMINO-CAFÊMICAS A discriminação Eै realizada utilizando os mesmos diagramas, os mesmos critérios e o mesmo vocabulário que os empregados para as associações cafêmicas. Os subtipos e as variantes das associaçöes aluminocafêmicas são então, em princípio, os mesmos que os das associaçōes cafêmicas. Todavia, o fato das associaçōes aluminocafêmicas estarem, de uma forma quase geral, exclusivamente compostas de termos claros, torna pouco provável a existência, no meio dessas associações, de variantes subalcalinas escuras ou alcalinas saturadas, ou ainda de subtipos toleíticos comportando gabros ou dioritos. Em contrapartida, um subtipo granito-trondhjemítico pode existir aqui (sua definição é dada no "Glossário").

\section{DISCRIMINAÇÃO DAS DIFERENTES ASSOCIAÇŌES}

ALUMINOSAS As associaçōes aluminosas são geralmente constituídas por rochas com duas micas ou com biotita. Essa relativa uniformidade de composição mineralógica esconde uma surpreendente diversidade tipológica (La Roche et al. 1980, Stussi et al. 1981) e seria, no momento, ilusório e arbitrário aplicar-lhes um método de classificação rígido e muito estruturado. Por isso, em vez de uma verdadeira classificação, propomos aqui um conjunto de critérios complementares, importantes de se considerar para alcançar a definição exaustiva de uma associação aluminosa. A hierarquia interna desse conjunto de critérios pode variar segundo a natureza do problema tratado (cartografia, petrogênese, potencialidades metalogênicas...) e a regiảo estudada, mas nenhum deles deve ser negligenciado a priori.

A lista dos critérios propostos para a discriminação das diferentes associaçöes aluminosas $\varepsilon$ a seguinte:

\section{CRITÉRIOS}

NATUREZA DAS ASSOCIAÇŌES

-Carga em quartzo $\quad\left\{\begin{array}{l}\text { rica em quartzo } \\ \text { banal em quartzo } \\ \text { pobre em quartzo }\end{array}\right.$

- Carga em coloridos

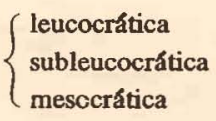

-Razão dos alcalinos

$$
\left\{\begin{array}{l}
\text { potássico } \\
\text { sodi-potássico } \\
\text { sódico }
\end{array}\right.
$$

-Relação quartzo-colo- $\left\{\begin{array}{l}\text { com evolução sflico-potássica } \\ \text { com evoluçăo sílico-sódica } \\ \text { com evoluçãa silicosa } \\ \text { com evoluçăo potássica } \\ \text { com evoluçăo sớdica } \\ \text { com quartzo decrescente } \\ \text { sem evolução significativa }\end{array}\right.$

-fndice aluminoso

(muito fortemente aluminosa fortemente aluminosa medianamente aluminosa fracamente aluminosa muito fracamente aluminosa

\section{- Localização e inclinação no diagrama dos minerais caracteristicos}

-Características das amostras (nomenclatura, particularidades químicomineralógicas, ....)

A definição dos cinco primeiros critérios desta lista é dada no "Glossário" e nas figuras 7 e 8. Os dois últimos são explicitados em Debon \& Le Fort (1983). Todos eles, enfim, são ilustrados pelos exemplos dados no item de Aplicação para cinturōes do Himalaia.

CRITÉRIOS ADICIONAIS Critérios suplementares podem ser integrados aos já apresentados para definir as diferentes categorias de associações magmáticas. De fato, da mesma forma que há granitos e granitos, há também associações cálcio-alcalinas e associações calcialcalinas ou associaçōes subalcalinas claras e associações subalcalinas claras etc. $\mathrm{Na}$ prática, isso significa que a definição precisa de uma associação deve possuir uma descrição precisa dos termos que a compõem. Partindo dessa descrição, distinções fundadas, por exemplo, sobre o carăter magnesiano ou ferrifero ("Glossário"; Debon \& Le Fort 1988), ou sobre a natureza do termo petrográfico dominante poderāo ser levadas em conta.

Entre as associaçöes estudadas, algumas poderão apresentar caracteres intermediários entre um e outro tipo, ou subtipo ou variante. Em vez de querer ligar a todo custo tais associações a uma categoria bem determinada, convém descrevê-las como transicionais entre os diferentes tipos, ou subtipos, ou variantes. Essa atitude se justifica perfeitamente à medida que, na natureza, as diferentes categorias de rochas ou de associaçōes não constituem entidades bem delimitadas, mas formam um continuum 


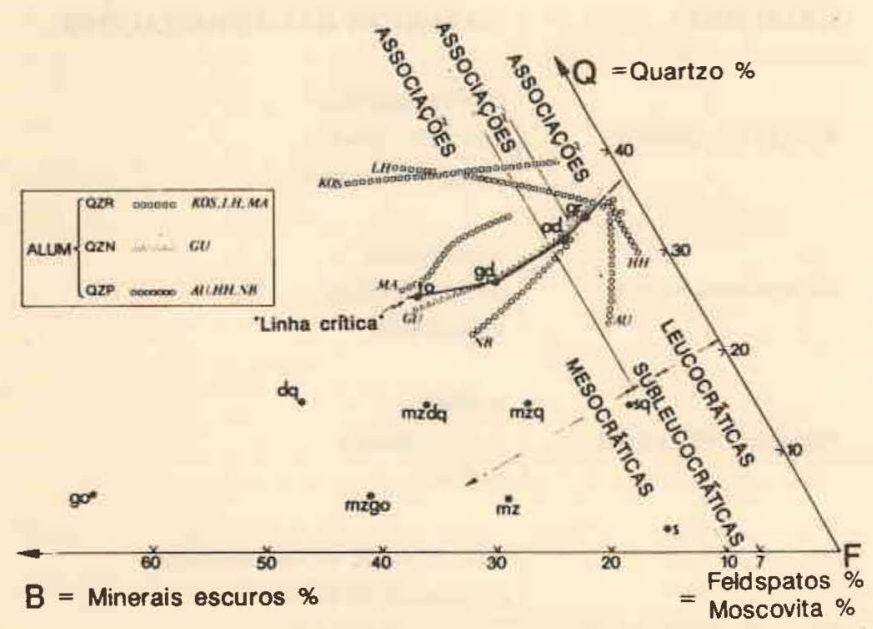

Figura 7 -Aplicação do diagrama triangular $Q-B-F$ - (Fig. 3) para a discriminação das associações de tipo aluminoso (ALUM). Este diagrama permite distinguir, em função de sua carga em quartzo, os três principais subtipos de associações aluminosas: rica em quartzo (QZR), banal em quartzo $(Q Z N)$ e pobre em quartzo $(Q Z P)$, correspondendo a associaçōes aluminosas respectivamente situadas acima, proximo e abaixo da linha crítica (ver texto e "Glossário"). Permite também (tanto como o diagrama da figura 8) classificar as associaçōes aluminosas em funçāo de sua carga em minerais coloridos em: leucocráticas, subleucocráticas e mesocráticas (ver texto $e$ "Glossário"). Outros critérios intervêm na discriminação das diferentes associações aluminosas, mas não podem ser apreendidos neste triângulo. Os exemplos representados aqui sāo os seguintes: $A U$, pluton d'Aureil, Maciço Central, França (Grandclaude et al. 1976, La Roche et al. 1980); HH, plúton do Manaslu, Alto Himalaia, Nepal (Le Fort 1973, 1981); KOS, tipo $S$ do batólito de Kosciusko, Austrália (Hine et al. 1978); LH, cinturão plutônico do Baixo Himalaia (Le Fort et al. 1983); MA, plúton da Margeride, Maciço Central, França (Couturié 1977); NB, grupo de plútons a biotita do batólito axial do Nuristão, Afeganistāo (Debon et al. 1987). Segundo Debon \& Le Forte (1983)

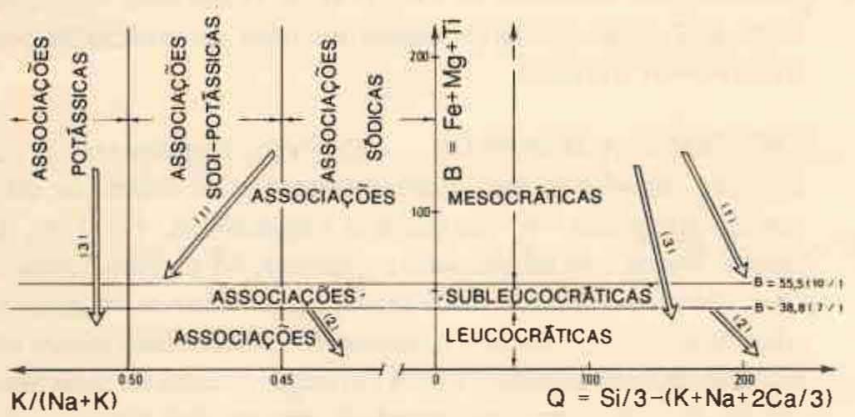

Figura 8-Aplicaçāo do diagrama $B=F e+\dot{i g}+$ Ti função de $Q=\mathrm{Si} / 3-(\mathrm{K}+\mathrm{Na}+2 \mathrm{Ca} / 3)$ e de $\mathrm{K} /(\mathrm{Na}+\mathrm{K})$ à discriminação das associaçōes de tipo aluminoso. Os parâmetros são expressos em átomo-grama $\times 10^{3}$ (milcátion) em $100 \mathrm{~g}$ de rocha. Este duplo diagrama permite classificar as associaçóes em função de três critérios: carga em coloridos (B), razão dos álcalis $K /(\mathrm{Na}+K)$ e relações quartzo $(Q)$-coloridos $(B)$-álcalis $\mathrm{K} /(\mathrm{Na}+\mathrm{K})$ (ver texto e "Glossário"). Os três exemplos representados aqui correspondem a associações, respectivamente: (1) mesocrática, sodi-potássica, com evolução sllicopotássica; (2) leucocrática, sódica, com evolução sllico-sódica; e (3) mesocrática até leucocrática, potássica, com evolução exclusivamente silicosa. Segundo Debon \& Le Fort (1983)

\section{APLICAÇĀO PARA TRÊS CINTURÕES PLUTÓNICOS DO HIMALAIA, A SUL DO TIBETE Somente uma ex-} posição sumária dessa aplicação será apresentada aqui. Para mais detalhes, referir-nos-emos a Debon et al. (1984, 1986).

No sul do país tibetano, três grandes cinturōes plutonicos se sucedem do norte para o sul: Trans-Himalaia, Norte-Himalaia e Alto-Himalaia (Figs. 9 e 10).

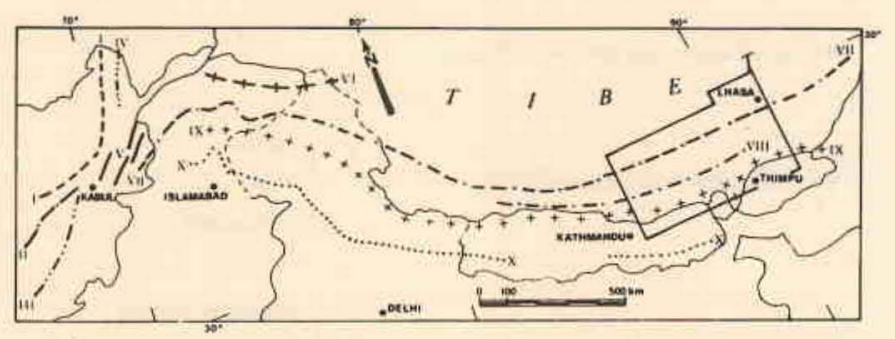

Figura 9-Mapa esquemático dos principais cinturōes plutônicos (numerados de I a X) localizados na borda norte do subcontinente indico. $O$ domínio que nos interessa aqui (Fig. 10) enquadrado. Três cinturões o atravessam: Trans-Himalaia (VII), Norte-Himalaia (VIII) e Alto Himalaia (IX). Segundo Debon et al. (1986)

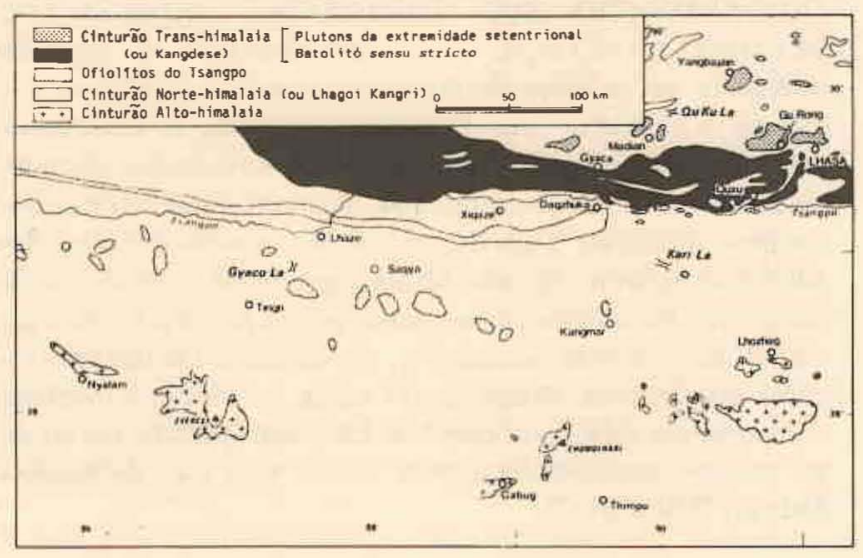

Figura 10 - Mapa esquemático dos três cinturões plutônicos do Himalaia, a sul do Tibete. Segundo Debon et al. (1984)

Cinturão (Batólito) do Trans-Himalaia Os resultados apresentados tratam de uma seção efetuada através do batólito sensu stricto, passando por Quxu, a Sudoeste de Lhasa (Fig. 10). Os dados químico-mineralógicos junto aos dados de campo permitem distinguir cinco conjuntos plutônicos (designados pelas anotaçōes 1a, 1b, 2, 3 e 4 sobre as figuras 11 a 13).

TIPOLOGIA DAS AMOSTRAS Variáveis de um conjunto para outro, as rochas encontradas são gabros, quartzo-dioritos, quartzo-monzodioritos, quartzo-monzonitos, granodioritos e adamelitos (Fig. 11). 


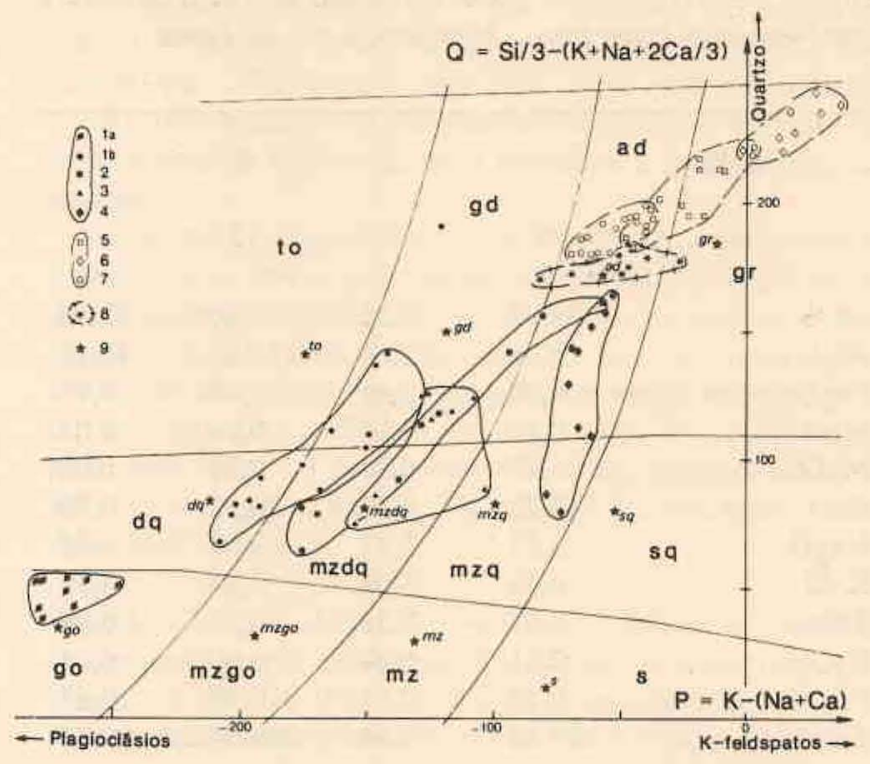

Figura 11 - Distribuição de alguns conjuntos plutônicos do Himalaia, a sul do Tibete no diagrama de nomenclatura (Figs. $l$ e 5). $1 a, 1 b, 2,3,4$ : conjuntos plutônicos reconhecidos no batolito do Trans-Himalaia sensu stricto, ao longo de uma seção passando por Quxu (Fig. 10); 5 a 7: cinturão do NorteHimalaia, com: 5 = plúton paleozbico de Kangmar; $6=$ plúton paleoźico de Gyaco La; 7 = plúton cenoźrico do Gyaco La; 8 = cinturão cenozóico do Alto Himalaia, plúton de Lhozhag; 9 = composições tipicas tomadas como referências (ver tabela 1). Parâmetros e anotaçōes como na figura 1 (Segundo Debon et al. 1984,1986)

Essas rochas são geralmente metaluminosas e localizadas no setor IV do diagrama dos minerais característicos (Fig. 12). Tal localização sugere serem elas são constituídas notadamente de biotita e de anfibólio \pm piroxênio (Fig. 2). O microscópio confirma esta composição e permite acrescentar que o esfeno é freqüente. Algumas amostras são fracamente peraluminosas e se localizam no setor III (ou seja, o das rochas com biotita).

A essas características maiores, será necessário adicionar uma descrição das outras particularidades químico-mineral6gicas de cada tipo de rocha. Assim, levando em conta apenas os termos gabróicos (conjunto 1a; Fig. 11), podemos dizer com precisão que se trata de gabros empobrecidos em coloridos mas excedentes em feldspatos (Fig. 13). Além disso, o conhecimento de sua composição química (análise no 1 da tabela 3 permite acrescentar, por comparação com a composição gabróica de referência (Tab. 1), que são gabros empobrecidos em $\mathrm{Ca}, \mathrm{Cr}, \mathrm{Cu}, \mathrm{Ni}$ mas excedentes em allcalis (por excesso de $\mathrm{Na}), \mathrm{Si}, \mathrm{Al}, \mathrm{Sr}$ e com fraca razão $\mathrm{Mg} /(\mathrm{Fe}+\mathrm{Mg})$.

TIPOLOGIA DAS ASSOCIAÇÕES Os cinco conjuntos plutônicos trans-himalaianos apresentados aqui correspondem a associações magmáticas distintas (Figs. 11 a 13), todas as cinco tipicamente cafêmicas (Fig. 12) mas de natureza ora transicional entre o calcialcalino e o subalcalino (conjuntos 1a e 1b), ora mais ou menos francamente subalcalino claro (conjuntos 2, 3 e 4) (Figs. 11 e 13), magnesianas até ferríferas.

Os autores estão de acordo em considerar o Trans-Himalaia como um magmatismo de arco insular ou de margem continental ativa ligada à subducção de um oceano hoje representado pelos ofílitos do Tsangpo (Fig. 10). Sua idade, variável, aparenta ser do Mesozóico Superior ao Paleogeno.

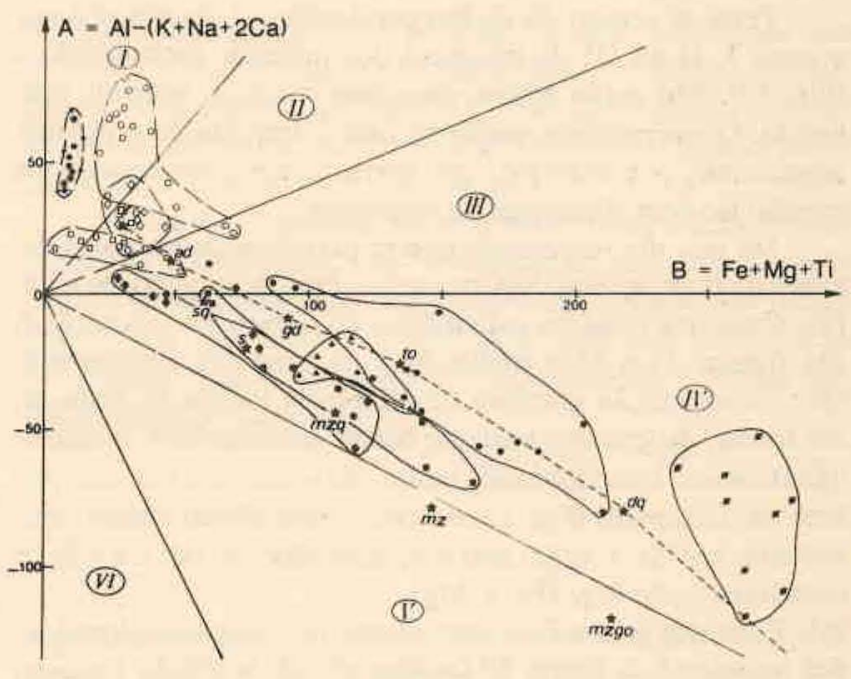

Figura 12 - Distribuição de alguns conjuntos plutônicos do Himalaia, a sul do Tibete no diagrama dos minerais caracteristicos (Figs. 2 e 4). Parâmetros e anotaçōes como nas figuras 2 e 4, simbolos análogos aos da figura 11. Segundo Debon et al. $(1984,1986)$

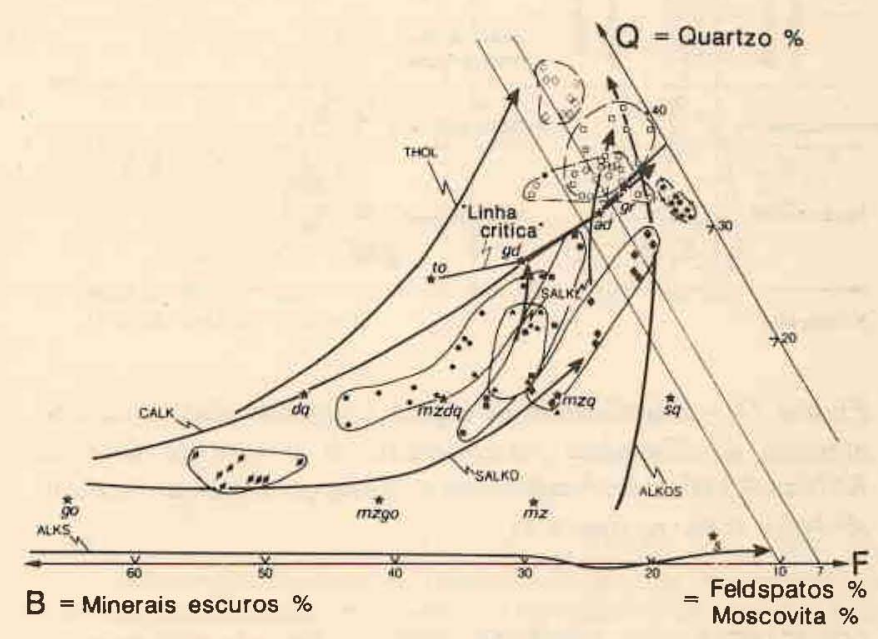

Figura 13 - Distribuição de alguns conjuntos plutônicos do Himalaia, a Sul do Tibete no diagrama triangular $Q-B-F$ (Figs. 3, 6 e 7). Para comparaçāo das associaçōes-tipo cafêmicas ou alumino-cafêmicas de natureza respectivamente tolettica (THOL), calcialcalina (CALK), subalcalina escura (SALKD), subalcalina clara (SALKL), alcalina saturada (AL$K S)$ e alcalina supersaturada (ALKOS) foram reportadas. $\mathrm{Pa}$ râmetros e outras anotaçōes como nas figuras 3, 6 e 7; simbolos como na figura 11. Segundo Debon et al. $(1984,1986)$

Cinturăo do Norte-Himalaja Situado a sul da sutura ofiolítica do Tsangpo (Fig. 10), em um contexto de crosta continental, este cinturāo do Norte-Himalaia é composto; compreende, de fato, granitoides paleozóicos (anotações 5 e 6 nas figuras 11 a 14) e granitóides cenozóicos (anotação 7). 
TIPOLOGIA DAS AMOSTRAS Os granitóides paleoz6icos correspondem principalmente a granitos e, acessoriamente, a adamellitos, enquanto os de idade cenozóica são exclusivamente adamelíticos (Fig. 11).

Trata-se sempre de rochas peraluminosas, localizadas nos setores I, II ou III do diagrama dos minerais característicos (Fig. 12). São então rochas com duas micas ou somente com biotita. $\mathrm{O}$ microscópio confirma essa interpretação e permite acrescentar, por exemplo, que certos adamellitos cenozóicos contêm também sillimanita ou andalusita.

No que diz respeito às outras particularidades químicomineralogicas, apenas dois exemplos serão desenvolvidos aqui. (a). Caso dos granitos paleozóicos do Gyaco La (anotação 6 das figuras 11 a 14 e análise $n=2$ da tabela 3): comparando com a composição granítica de referência (tabela 1), trata-se, em média, de granitos bastante banais em coloridos (e conseqüentemente leucocráticos), muito ricos em quartzo mas pobres em feldspatos (Fig. 13) e âlcalis (forte déficit sódico), excedentes em $\mathrm{Si}, \mathrm{Ba}, \mathrm{Rb}$ mas empobrecidos em $\mathrm{Al}, \mathrm{Ca}$ e $\mathrm{Sr}$, e com fraca razão $\mathrm{Mg} /(\mathrm{Fe}+\mathrm{Mg})$.

(b). Caso dos adamellitos cenozóicos do Gyaco La, localizados no setor I da figura 12 (análise no 3 da tabela 3): trata-se, em média, de adamelitos excedentes em quartzo mas empobrecidos em coloridos (leucocráticos), bastante banais em feldspatos + moscovita e em álcalis, deficitários em Ca, Ba e Sr, mas bastante ricos em $\mathrm{Rb}$, com razão $\mathrm{Mg} /(\mathrm{Fe}+\mathrm{Mg})$ bastante banal.

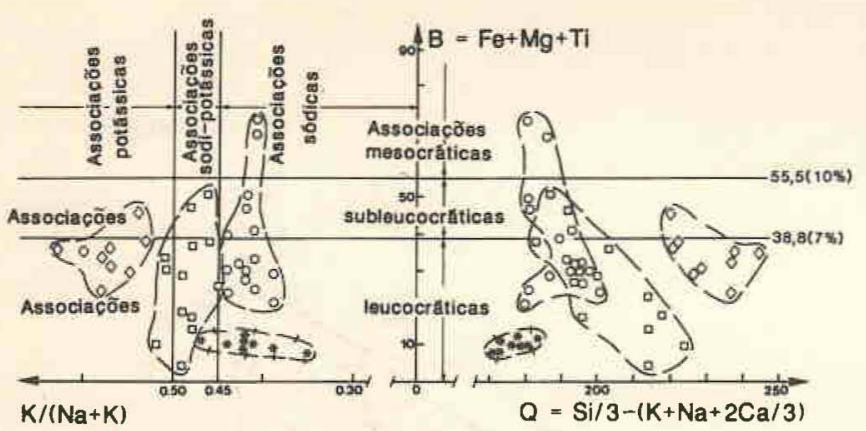

Figura 14 - Distribuição de alguns conjuntos plutônicos aluminosos do Himalaia no diagrama $B$ função de $Q$ e de $K /(N a+K)$ (Fig. 8). Parâmetros e anotaçôes como na figura 8; simbolos como na figura 11

TIPOLOGIA DAS ASSOCIAÇÕES Os três plátons norte-himalaianos apresentados aqui correspondem a associações magmáticas distintas (Figs. 11 a 14), todas três de tipo aluminoso (Fig. 12) mas de natureza sensivelmente diferente. De fato, uma análise mais profunda da tipologia dos três plutons mostra que:

(a). os dois plútons paleozóicos (Kangmar e Gyaco La, respectivamente designados pelas anotaçōes 5 e 6 sobre as figuras 11 a 14) correspondem a associaçōes mais ou menos ricas em quartzo (Fig. 13), leucocráticas a subleucocráticas (Fig. 13 ou 14), exclusivamente potássicas (Gyaco La) ou com dominante sodi-potássica (Kangmar) (fig. 14), com evolução silico - (potássica) (Fig. 14), fracamente (Kangmar) ou medianamente (Gyaco La) aluminosas (Fig. 12), distribuidas nos setores I, II e ds vezes III do diagrama dos minerais característi$\mathrm{cos}$, segundo um trend indeterminado (Gyaco La) ou com inclinação ligeiramente negativa (Kangmar) (Fig. 12), mais (Gyaco La) ou menos (Kangmar) FerriFeras ...
Tabela 3 - Composiçōes químicas médias de quatro unidades plutônicas dos cinturões do Himalaia, a sul do Tibete

\begin{tabular}{|c|c|c|c|c|}
\hline № análise & 1 & 2 & 3 & 4 \\
\hline $\mathrm{n}$ & 9 & 9 & 12 & 6 \\
\hline $\mathrm{SiO}_{2}$ & 50,65 & 76,32 & 72,76 & 73,66 \\
\hline $\mathrm{Al}_{2} \mathrm{O}_{3}$ & 18,76 & 12,08 & 15,32 & 15,18 \\
\hline $\mathrm{Fe}_{2} \mathrm{O}_{3} \mathrm{t}$ & 9,70 & 2,01 & 1,44 & 0,75 \\
\hline $\mathrm{MnO}$ & 0,17 & 0,04 & 0,04 & 0,03 \\
\hline $\mathrm{MgO}$ & 5,27 & 0,21 & 0,39 & 0,02 \\
\hline $\mathrm{CaO}$ & 9,20 & 0,59 & 0,98 & 0,70 \\
\hline $\mathrm{Na}_{2} \mathrm{O}$ & 3,57 & 2,47 & 3,63 & 4,05 \\
\hline $\mathrm{K}_{2} \mathrm{O}$ & 0,48 & 5,04 & 3,95 & 4,36 \\
\hline $\mathrm{TiO}_{2}$ & 0,87 & 0,28 & 0,22 & 0,03 \\
\hline $\mathrm{P}_{2} \mathrm{O}_{5}$ & 0,31 & 0,07 & 0,09 & 0,04 \\
\hline P.F & 0,50 & 0,43 & 0,79 & 0,63 \\
\hline Total & 99,48 & 99,54 & 99,61 & 99,45 \\
\hline $\mathrm{Ba}$ & 180 & 590 & 396 & 140 \\
\hline $\mathrm{Cr}_{\mathrm{r}}$ & 40 & $9-11$ & $>13->15$ & $0-10$ \\
\hline $\mathrm{Cu}$ & 22 & $11-19$ & 0-10 & $0-10$ \\
\hline $\mathrm{Ni}$ & 44 & $>6->12$ & $>10->13$ & $0-10$ \\
\hline $\mathrm{Rb}$ & $6-11$ & 311 & 226 & 308 \\
\hline $\mathrm{Sr}$ & 749 & 35 & 142 & 65 \\
\hline V & 234 & $14-25$ & $23-25$ & $6-11$ \\
\hline
\end{tabular}

Análise no 1: gabros do Trans-Himalaia (Quxu); no 2: granitos paleozbicos do Norte-Himalaia (Gyaco La); $n^{\circ}$ 3: adamellitos cenozóicos com duas micas (com moscovita $>$ biotita) do Norte-Himalaia (Gyaco La); $n^{\circ}$.4: adamellitos cenozbicos do AltoHimalaia (Lhozhag). $n=$ número de amostras analisadas. Análises quantométricas (K. Govindaraju, C.R.P.G., Nancy). $\mathrm{Fe}_{2} \mathrm{O}_{3} \mathrm{t}=$ ferro total, dosado sob forma férrica; $P . \mathrm{F} .=$ perda ao fogo. Os teores em elementos-traços são expressos em p.p.m. Análises extraídas de Debon et. al. $(1984,1986)$

(b). O pláton cenozóico (anotação 7 nas figuras 11 a 14) corresponde a uma associação rica a banal em quartzo (Fig. 13), leucocrática a mesocrática (Fig. 13 ou 14), exclusivamente sódica (Fig. 14), com evoluçâo mal definida, em primeiro lugar ślico-(potássica?) depois sódica com quartzo decrescente (Fig. 14), média a muito fortemene aluminosa (A oscila entre 23 e 81 átomos-g x 1033; Fig. 12), distribuída nos setores I, II e III do diagrama dos minerais característicos, segundo um trend com inclinação negativa ao nível dos termos mais coloridos e subvertical depois, magnesiana.

Os autores estão de acordo em atribuir a gênese de todos esses granitóides do Norte-Himalaia a anatexias de crosta continental.

Cinturão do Alto-Himalaīa Situado no sul do Norte-Himalaia (Fig. 9), este cinturão cenozóico é também localizado num contexto de crosta continental. $O$ exemplo escolhido para ilustrar sua tipologia químico-mineralógica é o pequeno pláton de Lhozhag (Fig. 10; anotação 8 nas figuras 11 a 14).

TIPOLOGIA DAS AMOSTRAS Os granitóides de Lhozhag são adamelitos às vezes granitos ou granodioritos (Fig. 11). 
Trata-se sempre de rochas peraluminosas, localizadas no setor I do diagrama dos minerais característicos (Fig. 12). Isso sugere que sejam rochas com duas micas com moscovita $>$ biotita (em volume). $\mathrm{O}$ microscópio confirma esse ponto de vista e permite adicionar que a turmalina e freqüente nessas rochas.

No que diz respeito às outras particularidades químicomineralógicas desses granitóides, apresentaremos aqui as da fácies adamelito (análise n 4 da tabela 3): comparando com a composição adamelítica de referência (Tab. 1), trata-se, em média, de adamelitos banais em quartzo, muito empobrecidos em coloridos (leucocráticos) mas excedentes em feldspatos + moscovita (Fig. 13) assim como em alcalis (excesso de $\mathrm{Na}$ e $\mathrm{Rb}$ ), pobres em $\mathrm{Ca}, \mathrm{Ba}, \mathrm{Cr}, \mathrm{Cu}, \mathrm{Ni}, \mathrm{Sr}$ e $\mathrm{V}$, com razão muito fraca $\mathrm{Mg} /(\mathrm{Fe}+\mathrm{Mg})$.

\section{TIPOLOGIA DA ASSOCIAÇÃO O plúton de Lhozhag} corresponde a uma associação tipicamene aluminosa (Fig. 12), pobre em quartzo (Fig. 13), muito leucocrática (Fig. 13 ou 14), essencialmente sódica (Fig. 14), com evolução muito fracamente marcada mas de caráter tipicamente sódico com decréscimo do quartzo (Fig. 14), em média fortemente aluminosa $\left(A=49\right.$ átomos-g $\times 10^{3}$ com oscilaçōes entre 40 e 66 ; Fig. 12), distribuída no setor I do diagrama dos minerais característicos segundo um trend subvertical (Fig. 12), muito ferrifera.

A gênese dos leucogranitóides do Alto-Himalaia parece ligada a uma anatexia parcial da crosta continental antiga ( $e . g$. Le Fort 1981, Le Fort et al. 1987).
TRANSPOSIÇÃO DA CLASSIFICAÇÃO PARA AS ROCHAS VULCÂNICAS COMUNS E A SUAS ASSOCIAÇÕES A classificação proposta ê diretamente transponível para o vulcanismo.

Ao nível da tipologia de uma amostra, basta para isso substituir a nomenclatura plutônica para seu equivalente vulcânico (vide legenda da fïgura 1) e lembrar sempre do fato de que as expressões mineralogicas dos dados químicos poderão, aqui, corresponder a fases virtuais.

Ao nível da tipologia de uma associação, a transposição se efetua diretamente, sem modificação das denominaçōes (fora aquelas implicando um vocabulário próprio das rochas plutônicas). Exemplo: uma associação cafêmica calcialcalina (ou granodiorítica) tornar-se-á uma associação cafêmica calcialcalina (ou riodacítica).

Agradecimentos Este trabalho deve muito às idéias levadas a tona e desenvolvidas por $\mathrm{H}$. de La Roche sobre a tipologia do magmatismo.

Nossos melhores agradecimentos para K. Govindaraju e para o Serviço E.D.T.A. do C.R.P.G. pelas análises químicas e seu tratamento automático; para J. Gerbaut e A. Legros, pelo cuidado na datilografia e na ilustração deste trecho; a Gleides V. Machado, pela revisão do português; e a Itanajara J. M. Silva, Contribuição no 713 pela datilografia nesta língua.

\section{REFERÊNCIAS BIBLIOGRÁFICAS}

CHAPPEL, B.W. \& WHITE, A.J.R. 1974. Two contrasting granite types. Pacif. Geol., 8:173-174.

COUTURIÉ, J.P. 1977. Le massif granitique de la Margeride (Massif Central français). Ann. Sci. Univ. Clermont, 62.

DEBON, F. \& LE FORT, P. 1983. A chemical-mineralogical classification of common plutonic rocks and associations. Trans. Roy. Soc. Edinburgh 73:135-149. (Earth Sci.)

DEBON, F. \& LE FORT, P. 1988. A cationic classification of common plutonic rocks and their magmatic association: principles, method, applications. Bull. Minéralogie, 111(5): (in press)

DEBON, F. \& LE FORT, P. 1984. Chemical-mineralogical classification of plutonic rocks associations. Examples from Southern Asia belts. In: SYMP. ON GEOLOGY OF GRANITES AND THEIR METALLOGENETIC RELATIONS, Nanjing, China, 1982. Proceed... Beijing, China Science Press. 293-311.

DEBON, F.; AFZALI, H.; LE FORT, P.; SONET, J.; ZIMMERMANN, J.L. 1987. Plutonic rocks and associations in Afghanistan: typology, age and geodynamic setting. Mém. Sci. de la Terre, 49, $132 \mathrm{p}$.

DEBON, F.; LE FORT. P.; SHEPPARD, S.M.F.; SONET, J. 1986. The four plutonic belts of the Transhimalaya-Himalaya: a chemical, mineralogical, isotopic, and chronological synthesis along a Tibet-Nepal section. J. Petrol., 27:219-250.

DEBON, F.; SONET, J.; LIU, G.H.; JIN C.W.; XU, R.H. 1984 Caracteres chimico-mineralogiques et datations par $\mathrm{Rb}-\mathrm{Sr}$ des trois ceintures plutoniques du Tibet méridional. In MERCIER J.L. e logique et géophysique de la croûte terrestre et du manteau supérieur du Tibet et de l'Himalaya. Paris, Centr. Natl. Rech. Sci., p. 309-317.

GRANDCLAUDE P.; MARCHAL, M.; LA ROCHE H. de. 1986. Les fichiers géochimiques du Centre de Recherches Pétrographiques et Géochimiques: leur contenu et les modalités de leur utilisation comme banques de données. Ind. Minér., 58:557-563.

HINE, R.; WILLIAMS, I.S.; CHAPPELL, B.W.; WHITE, A.J.R. 1978. Contrasts between I and S-type granitoids of the Kosciusko Batholith. J. Geol. Soc. Austr., 25:219-234.

LA ROCHE, H. de. 1964. Sur l'expression graphique des relations entre la composition chimique et la composition minéralogique quantitative des roches cristallines. Présentation d'un diagramme destiné à l'étude chimico-minéralogique des massifs granitiques ou granodioritiques. Application aux Vosges cristallines. Sci. de la Terre, 9:293-337.

LA ROCHE, H. de. 1966. Sur l'usage du concept d'association minérale dans l'étude chimique des roches: modèles chimiques, statistiques, représentations graphiques, classification chimicominéralogique. C.R. Acad. Sci. Paris, 262(D):1665-1668.

LA ROCHE, H. de. 1979. Muscovitisation deutérique, caractère alumineux des leucogranites et classification de granites subsolvus. Bull. Soc. Géol. Fr., 21:87-93.

LA ROCHE, H. de; STUSSI, J.M.; CHAURIS, L. 1980. Les granites à deux micas hercyniens français. Essais de cartographie et de corrélations géochimiques appuyés sur une banque de donnés. Implications pétrologiques et métallogéniques. Sci. de la Terre, 
LE FORT, P. 1973. Les leucogranite à tourmaline de l'Himalaya sur l'exemple du granite du Manaslu (Népal central). Bull. Soc. Géol. Fr., 15:555-561.

LE FORT, P. 1981. Manaslu leucogranite: a collision signature of the Himalaya. A model for its genesis and emplacement. J. Geophys. Res., 86:10545-10568 (Red Ser).

LE FORT, P.; CUNEY, M.; DENIEL, C.; FRANCE-LANORD, C.; SHEPPARD, S.M.F.; UPRETI, B.N.: VIDAL, P. 1987. Crustal generation of the Himalayan leucogranites. Tectonophysics, 134:39-57.

LE FORT, P.; DEBON, F.; SONET, J. 1983. The Lower Paleozoic "Lesser Himalayan" granitic belt: emphasis on the Simchar pluton of Central Nepal. In SHAMS F.A. ed. Granites of Himalaya, karakorum and Hindu Kush. Lahore, Punjab Univ., P. 235-255.

MOINE, B. 1974 Caractère de sédimentation et de métamorphisme de séries précambriennes épizonales à catazonales du centre de $\mathrm{Ma}$ dagascar (région d'Ambatofinandrahana). Approche structurale, pétrographique et spécialement géochimique. Mém. Sci. de la Terre, 31, $293 \mathrm{p}$.

\section{GLOSSÁRIO}

Associação: conjunto de amostras apresentando características comuns e proveniente de uma mesma estrutura f́nea (pláton, batólito, cinturâo plutônico, ....).

Associação alcalina (ou peralcalina), um dos quatro principais subtipos distintos no meio das associaçōes de tipo cafêmico ou aluminocafêmico, compreende três variantes: 1. associaçčo alcalina saturada escura: constitufda principalmente por termos escuros, podendo incluir gabros, dioritos, monzogabros, monzodioritos, monzonitos (sienitos) i.e. localizada nos quadrinhos $12,11,10$ (e 9) das figuras 1 e 5; situa-se perto da base do triângulo Q-B-F, mais ou menos paralelamente a esta (Fig. 6); 2. associaçäo alcalina (ou peralcalina) supersaturada clara: constitufda por termos claros, podendo incluir monzonitos, sienitos, quartzo-monzonitos, quartzo-sienitos, adamelitos, granitos (i.e. localizada nas casas 10, 9, 6, 5, 2 e 1 das figuras 1 e 5); dentro do triângulo QB-F (Fig. 6) enraíza-se abaixo da linha gabro-granito e se desenvolve vertical ou paralelamente ao lado Q-F, próximo deste. Uma associação peralcalina é um caso particular da variante alcalina supersaturada; pelo menos uma parte dos termos que a compóem coresponde a rochas peralcalinas (i.e. com $(\mathrm{Na}+\mathrm{K}) \mathrm{Al}$, em atomo-g ou cátion); 3. associação alcalina (ou peralcalina) composta: apresenta ao mesmo tempo os caracteres das associaçōes alcalinas (ou peralcalinas) saturadas e supersaturadas.

Associaçăo aluminosa: um dos três grandes tipos de associaçōes magmáticas, $\varepsilon$ inteiramente composta de termos peraluminosos; dentro do diagrama dos minerais caracterf́sticos (Fig. 4), seu trend apresenta uma curva vertical, positiva ou ligeiramente negativa.

Associaçăo alu mino-café mica: um dos três grandes tipos de associações magmáticas principal ou totalmente compostas de termos claros peraluminosos; no diagrama dos minerais caracterfíticos, seu trend apresenta tipicamente uma inclinação negativa e se enrafza ao nfvel de seus termos mais coloridos, no - ou próximo do-domínio metaluminoso.

Associação banal em quartzo: um dos três principais subtipos distinguidos entre as associaçöes de tipo aluminoso; relativamente pouco freqüente; pode incluir (trondhjemitos excepcionalmente), (granodioritos), adamellitos, granitos (i.e. geralmente localizada nas casas 2 e 1 da figura 1); apresenta cargas banais de quartzo, feldspato + muscovita e alcalinos; dentro do triângulo Q-B-F (Fig. 7), localiza-se na proximidade imediata da linha crítica.
SHAND, S.J. 1927 Eruptive rocks. Their genesis, composition, classification and their relation to ore-deposits. London, Murby.

STRECKEISEN, A.L. 1974 Classification and nomenclature of plutonic rocks. Geol. Rundsch., 63:773-786.

STRECKEISEN, A.L. 1976. To each plutonic rock its proper name. Earth Sci. Rev., 12:1-33.

STUSSI, J.M.; MOREAU, M.; LA ROCHE, H. de 1981. Typologie chimique et cartographie régionale des granitoídes varisques des zones uranifères françaises: relations avec les teneurs géochimiques en uranium et thorium. In: INTERN. GEOL. CONGR., 26, Paris, 1980. Proceed ..., Beograd, Geoinstitut, p. 5-20. (Section 13, theme 2.2: Metalogenesis of Uranium).

MANUSCRITO 449 Recebido em 10 de abril de 1987 Revisão aceita em 30 de outubro de 1987

Associação cafê mica: um dos três grandes tipos de associaçōes magmáticas, prncipal ou totalmente composta de termos metaluminosos; no diagrama dos minerais característicos (Fig. 4), seu trend apresenta uma inclinação negativa e seus termos claros penetram frequientemente no domínio peraluminoso.

A sso ciação calcialcalina (ou granodiorttica): umi dos quatro principais subtipos distinguidos entre as associaçбes de tipo cafemico ou alumino-cafêmico $\varepsilon$ constituída por termos comuns podendo incluir (gabros), (monzogabros hipofeldspáticos), dioritos, quartzo-dioritos, quartzo-monzodioritos hipofeldspáticos, tonalitos, granodioritos, adamelitos (granitos), i.e. localizada nas casas (12), (11), 8, 7, 4, 2, (1) das figuras 1 e 5 ; nunca possui monzogabros, monzodioritos, monzonitos ou sienitos típicos, quer sejam quartzfferos ou nāo; no triângulo Q-B-F (Fig. 6), localiza-se na proximidade da linha gabro-granito.

A sso ciaçăo ferrffera: em um diagrama $\mathrm{Mg} /(\mathrm{Fe}+\mathrm{Mg})$ função de $\mathrm{B}=$ $\mathrm{Fe}+\mathrm{Mg}+\mathrm{Ti}\left(\mathrm{em}\right.$ átomo-grama $\times 10^{3}$ e com $\mathrm{Fe}=$ ferro total): qualquer associaçāo localizada abaixo da linha que une os pontos das composiçóes granítica, adamelítica, granodiorítica, tonalitica, quartzodiorítica e gabróica tomados como referência (Tab. 1; Debon e Le Fort 1988).

A sso ciação granito-tron dhje m/tica: subtipo raro das associaçóes de tipo alumino-cafêmico, tipicamente constituída por leucogranitos, leucoadamelitos, leucogranodioritos e leucotonalitos (i.e. trondhjemitos) ricos em quartzo (i.e. localizada nas casas 1 a 4 das figuras 1 a 5); dentro do triângulo Q-B-F, seus termos săo agrupados no domínio leucocrático e rico em quartzo.

Associaçăo magnesiana: em um diagrama $\mathrm{Mg} /(\mathrm{Fe}+\mathrm{Mg})$ funçăo de $\mathrm{B}=\mathrm{Fe}+\mathrm{Mg}+\mathrm{Ti}$ (em átomo-grama $\times 10^{3}$ e com $\mathrm{Fe}=$ ferro total): qualquer associação localizada acima da linha que une os pontos das composiçōes granítica, adamelítica, granodiorftica, tonalitica, quartzodiorf́tica e gabróica tomadas como referência (Tab. L, Debon \& Le Fort 1988).

Associação pobre e m quartzo: um dos três principais subtipos distinguidos entre as associaçóes de tipo aluminoso; bastante frequiente; pode incluir (trondhjemitos, raramente), (granodioritos), adamellitos (a maioria das vezes predominantes), granitos (i.e. muitas vezes principalmente localizada na casa 2 da figura 1 ); $e ̂$ relativamente pobre em quartzo mas rico em feldspatos + moscovita e alcalinos dentro do triângulo Q-B-F (Fig. 7), localiza-se abaixo da linha crítica.

A ssociação rica e m quartzo: um dos três principais subtipos distinguidos entre as associaçōes de tipo aluminoso; freqüente; pode incluir 
(trondhjemitos, excepcionalmente), (granodioritos), adamellitos, granitos (muitas vezes, exclusivamente) (i.e. geralmente localizada na casa 2 e/ou somente 1 da figura 1); $\varepsilon$ rica em quartzo, mas empobrecida em feldpatos + moscovita e álcalinos; dentro do triångulo Q-B-F (Fig. 7), localiza-se acima da linha crftica.

A ssociaçăo subalcalina (ou monzon(tica): um dos quatro principais subtipos distinguidos entre as associaçøes de tipo cafemico ou alumino-cafemico; compreende três variantes: 1. associação subalcalina escura: constiturda principalmente de termos escuros, podendo incluir gabros, dioritos, monzogabros, monzodioritos, (raramente monzonitos), quartzo monzodioritos, quartzo monzonitos, (quartzo sienitos) i.e. localizada nas casas 12, 11 (10), 7,6 (5) das figuras 1 e 5; dentro do triângulo Q-B-F (Fig. 6), situa-se abaixo dá linha gabro-granitos; 2. associação subalcalina clara: constiturda por termos claros, podendo incluir (quartzo-monzodioritos), quartzo-monzonitos, quartzo-sienitos assim como (leucotonalitos, excepcionalmente), granodioritos, adamelitos e granitos ricos em feldspatos e álcalis i.e. localizada nas casas (7), 6, 5, (4), 3, 2 e 1 das figuras 1 e 5; dentro do triângulo Q-B-F (Fig. 6), seu trend começa abaixo da linha gabro-granito e continua seguindo uma inclinação muito forte, empinada, vertical ou mais ou menos paralela ao lado Q-B; 3. associação subalcalina composta: apresenta ao mesmo tempo os caracteres das associaçర్es subalcalinas escuras e claras.

Associaçáo toleftica (ou gabro-trondhje mftica): um dos quatro principais subtipos distinguidos entre as associaçбes de tipo cafemico ou alumino-cafêmico; qualquer associação exclusivamente supersaturada constituida por termos pobre em $\mathrm{K}_{2} \mathrm{O}$ : gabros, dionitos, quartzodioritos, tonalitos, trondhjemitos (i.e. localizada nas casas 12, 8, 4 assim como no domínio hiperquartzoso das figuras 1 e 5), qualquer que seja o seu iron trend e as proporçס̋es relativas de seus diferentes termos; geralmente, dentro do triângulo Q-B-F (Fig. 6) mostra um déficit feldspático, localiza-se acima da linha gabro-granito e apresenta um trend empinado, mais ou menos paralela ao lado Q-B. No caso de associaçōes exclusivamente gabróicas (i.e. inteiramente localizada na casa 12 da figura 1), o diagrama de nomenclatura $\varepsilon$ insuficiente para discriminar, somente a partir dele, as de natureza tolef́tica das de outra natureza (subalcalina escura, alcalina seturada calcilcalina); a localização e o trend de tais associaçóes dentro do triângulo Q-B-F tornam-se então determinantes para se efetuar a discriminaçăo.

Carga em coloridos (B) de uma associaçăo aluminosa: um dos critérios de discriminação no seio das associaçōes aluminosas: associaçăo leucocrática ( $\mathrm{B}<7 \%$, i.e. $\mathrm{Fe}+\mathrm{Mg}+\mathrm{Ti}<38,8$ átomos-g $\times 10^{3}$ para $100 \mathrm{~g})$; subleucocrática $(7 \% \leqslant \mathrm{~B} \leqslant 10 \%)$; mesocrática (B $>10 \%$; i.e. $\mathrm{Fe}+\mathrm{Mg}+\mathrm{Ti}>55,5)$.

Carga em quartzo de uma associaçăo aluminosa: principal critério de discriminaçăo no seio das associaçóes aluminosas; seguindo sua posiçăo acima, vizinha ou abaixo da linha crítica do triangulo Q-BF (Fig. 7), uma associaçăo aluminosa é dita rica, banal ou pobre em quartzo.

Index aluminoso de uma associaçăo aluminosa: um dos critérios de discriminaçăo no seio das associaçōes aluminosas; definido através do valor médio ou dos valores extremos do parâmetro $\mathrm{A}=\mathrm{Al}$ $(\mathrm{K}+\mathrm{Na}+2 \mathrm{Ca})\left(\mathrm{em}\right.$ átomo-g $\times 10^{3}$ ou milicátions para $\left.100 \mathrm{~g}\right)$ dos ter- mos que compōem a associaçãa distinguem-se as associaçōes muito fracamente aluminosas $(A<10)$, fracamente aluminosas $(10 \leqslant A<20$ ), medianamente aluminosas $(20 \leqslant \mathrm{~A}<40)$, fortemente aluminosas $(40 \leqslant A<60)$ e muito fortemente aluminosas $(A \geqslant 60)$.

Linha crftica: dentro do triângulo Q-B-F (Fig. 7), $€$ a linha que une os pontos das composiçōes granftica, adamellftica, granodiorf́tica e tonalítica tomadas como referência (Tab. 1). Ela é utilizada para a discriminação dos três principais subtipos de associaçōes aluminosas: rica em quartzo, banal em quartzo e pobre em quartzo.

Metaluminosa: rocha com $(\mathrm{K}+\mathrm{Na}+2 \mathrm{Ca}) \geqslant \mathrm{Al}(\mathrm{em}$ átomo-g ou cátion), i.e. com um valor nulo ou negativo do seu parâmetro A.

Peraluminosa: rocha com $(\mathrm{K}+\mathrm{Na}+2 \mathrm{Ca})<\mathrm{Al}$ (em átomo-g ou cátion), i.e. com um valor positivo do seu parâmetro A (Shand 1927).

Razăo dos álçalis de uma associaçăo aluminosa: um dos criterios de discriminação no seio das associaçōes aluminosas; definido pela razāo $\mathrm{K} /(\mathrm{Na}+\mathrm{K})$; distinguem-se associaçôes potóssicas $\mathrm{K} /(\mathrm{Na}+$ $\mathrm{Ca}) \geqslant 0,50$, sodi-potássicas $0,45 \leqslant \mathrm{~K} /(\mathrm{Na}+\mathrm{K})<0,50$ e sódicas $\mathrm{K} /(\mathrm{Na}$ $+\mathrm{K})<0,45$ em átomo-g ou cátion.

Relação quartzo - coloridos - álcalis de uma associação alu minosa: um dos critérios de discriminação no seio das associaçōes aluminosas; critério baseado na evoluçăo da carga em quartzo (Q) e na razăo dos álcalis $\mathrm{K} /(\mathrm{Na}+\mathrm{K})$ de uma associação, dos seus termos mais coloridos aos mais claros (Fig. 8); distinguem-se assim associaçōes aluminosas com evoluçāo: sflico-potássica (crescimento de $\mathrm{Q}$ e da razão dos álcalis), sflico-sódica (crescimento de $\mathrm{Q}$ e decrescimo da razāo dos álcalis), exclusivamente silicosa (crescimento de $Q$ sem variaçäo significativa da razăo dos álcalis), exclusivamente potássica (crescimento da razāo dos álcalis sem variação significativa de Q), exclusivamente sódica (decréscimo da razão dos álcalis sem variação significativa de Q), com quartzo decrescente, com ou sem variação da razão dos álcalis e sem variação significativa de $Q$ e da razão dos álcalis.

Rocha plutónica co mu m: rocha f́gnea granular saturada ou supersaturada em sflica. Ela engloba os granitóides e as rochas plutônicas associadas frequientemente encontradas nos cinturōes plutônicos.

Subtipo (de uma associaçăo magmática): subdivisão maior entre as associaçōes de tipo cafermico, alumino-cafemico ou aluminoso; há quatro principais subtipos entre as associaçöes cafêmicas ou aluminocafemicas: toleftica (ou gabro-trondhjemftica), calcialcalina (ou granodiorítica), subalcalina (ou monzonf́tica) e alcalina; três principais subtipos entre as associações aluminosas: rica em quartzo, banal em quartzo e pobre em quartzo.

Tipo (de u ma asso ciação magmática): divisão maior entre associaçбes magmaticas; dois principais tipos (cafemica e aluminoso) e um tipo intermediário (alumino-cafêmico).

Trond hje mito: tonalito cuja carga em minerais coloridos e $10 \%$.

Variante (de uma associação magmática): subdivisão de um subtipo.

É relativamente fácil descobrir se um cientista usa suas palavras com precisão: em nosso curso... orientamos os alunos na busca dos verbos sugerir, indicar, revelar, demonstrar, comprovar em contextos em que o autor se refere ao resultado de pesquisas. Assim, uma pesquisa (apenas) sugere/indica/revela algo ou; ao contrário, demonstra/comprova/enfatiza algo? O uso desses verbos (e outros, que o leitor poderá acrescentar à lista) diz muita coisa sobre a exatidảo lexical de um cientista. 